\title{
Variability of lean mass depletion in chronic obstructive pulmonary disease
}

\author{
H. Burke ${ }^{1,2,3}$, M. M. Wojtas ${ }^{1,2,3}$, T. Wilkinson ${ }^{1,3}$ and S. A. Wootton ${ }^{1,2}$ \\ ${ }^{1}$ University Hospital Southampton NHS Foundation Trust, Southampton SO16 6YD, UK, ${ }^{2}$ NIHR Southampton \\ Biomedical Research Centre, Southampton SO16 6YD, UK and ${ }^{3}$ NIHR Southampton Respiratory Biomedical Research \\ Unit, Southampton SO16 $6 Y D, U K$
}

Chronic obstructive pulmonary disease (COPD) is a leading cause of morbidity and mortality worldwide. Skeletal muscle wasting is a clinically relevant systemic manifestation of COPD that predicts morbidity and mortality independently from the severity of lung function $^{(1)}$. Loss of skeletal muscle mass is observed in about $20-40 \%$ of COPD patients ${ }^{(2)}$ and this is associated with a $50 \%$ reduction in median survival ${ }^{(3)}$. Given the importance of recognising lean mass depletion in this population, it is key that clinicians have accurate and reproducible measures to identify skeletal muscle wasting. An index of fat free mass (FFMi) is used to estimate lean mass and can be measured by several techniques including bioelectrical impedance analysis (BIA). In the literature, there are multiple proposed cut-offs of FFMi to identify lean mass depletion. Our aim was to study variability of FFMi in COPD patients and investigate the effect of applying the different proposed cut-off values for lean mass depletion.

We systematically searched the Web of Science database using broad search terms to identify studies from 1990 to 2014 with data on FFMi in COPD patients. The time period was chosen as the concept of FFMi was first described in $1990^{(4)}$. From an initial 94 articles identified, 14 studies provided data on mean and standard deviation (SD) values for FFMi in male COPD patients and of these, 11 also provided results for female COPD patients. Using the mean and SD values for FFMi, a cumulative normal distribution was produced with Excel software in order to demonstrate the implications of using different cut-offs identified in the systematic review on the percentage of patients categorised as lean deplete.

12 of the 14 studies identified in the review used BIA as their method for determining fat free mass. The remainder used DXA and skinfold thickness respectively. The mean FFMi for male COPD patients ranges from $16 \cdot 8 \mathrm{~kg} / \mathrm{m}^{2}$ to $19 \cdot 8 \mathrm{~kg} / \mathrm{m}^{2}$. Three different lean deficit cut-offs for men were identified in the review, $16 \mathrm{~kg} / \mathrm{m}^{2}, 17 \mathrm{~kg} / \mathrm{m}^{2}$ and $17.4 \mathrm{~kg} / \mathrm{m}^{2}$. Similar variability was found in the female results, with the mean FFMi varying from $14.7 \mathrm{~kg} / \mathrm{m}^{2}$ to $18.2 \mathrm{~kg} / \mathrm{m}^{2}$. There were also 3 different lean deficit cut offs $\left(14 \mathrm{~kg} / \mathrm{m}^{2}, 14.6 \mathrm{~kg} / \mathrm{m}^{2}\right.$ and $\left.15 \mathrm{~kg} / \mathrm{m}^{2}\right)$. Further analysis showed when using an FFMi cut-off of $16 \mathrm{~kg} / \mathrm{m}^{2}$, the percentage of male COPD patients identified as lean deplete varied from $4.6 \%$ to $36.9 \%$. This increased from $19.6 \%$ to $65.5 \%$ when an FFMi cut-off of $17.4 \mathrm{~kg} / \mathrm{m}^{2}$ is used. A similar spread of data was seen in the female results.

This review and analysis highlights the complexity of diagnosing lean depletion accurately in the COPD population. The combined effect of the variability in FFMi across different COPD populations together with different cut-offs makes it extremely difficult to know with certainty what the true prevalence of lean depletion is. Further work needs to be done to establish an accurate method of diagnosing lean depletion in COPD patients, taking into account the patient population, gender and age.

1. Swallow EB, Reyes D, Hopkinson NS et al. (2007) Thorax 62, 115-120.

2. Schols AM, Soeters PB, Dingemans AM et al. (1993) Am Rev Respir Dis 147, 1151-1156.

3. Schols AM, Broekhuizen R, Weling-Scheepers CA et al. (2005) Am J Clin Nutr 82, 53-59.

4. VanItallie TB, Yang MU, Heymsfield SB et al. (1990) Am J Clin Nutr 52, 953-959. 